\title{
ATIVIDADES EXPERIMENTAIS NOS ANOS INICIAIS DO ENSINO FUNDAMENTAL: ANÁLISE EM UM CONTEXTO COM ESTUDANTE CEGO
}

\author{
Beatriz Biagini* \\ Fábio Peres Gonçalves**
}

RESUMO: A pesquisa teve como objetivo investigar limites e potencialidades de uma proposta de experimentação para o ensino e aprendizagem em Ciências da Natureza em uma turma do $3^{\circ}$ ano do ensino fundamental formada por videntes e um aluno cego. A proposta foi fundamentada em discussões da literatura. As fontes de informações para análise qualitativa foram videogravações das aulas e registros escritos dos alunos. No exame das informações, orientado pelos procedimentos da Análise Textual Discursiva, identificaram-se potencialidades à aprendizagem do trabalho em grupo e à explicitação dos conhecimentos discentes sobre os assuntos em estudo. Houve limites no questionamento dos conhecimentos iniciais, no favorecimento de reflexões diante das observações, na participação do estudante cego nos procedimentos experimentais e na promoção de debates.

Palavras-chave: Experimentação. Cegos e videntes. Ensino de ciências da natureza.

\section{ACTIVIDADES EXPERIMENTALES EN LOS AÑOS INICIALES DE LA ENSEÑANZA ELEMENTAL: ANÁLISIS EN UN CONTEXTO CON ESTUDIANTE CIEGO}

RESUMEN: La investigación tuvo como objetivo examinar los límites y las potencialidades de una propuesta de experimentación para la enseñanza y el aprendizaje en Ciencias de la Naturaleza en una clase del $3^{\circ}$ año de la enseñanza elemental formada por videntes y un alumno ciego. Se fundamentó la propuesta en discusiones de la literatura. Las fuentes de información para el análisis cualitativo fueron videograbaciones y apuntes de los alumnos. En el examen de las informaciones, orientado por los procedimientos del Análisis Textual Discursivo, se identificaron potencialidades al aprendizaje del trabajo en grupo y a la explicación de los conocimientos discentes acerca de asuntos en estudio. Hubo límites en el cuestionamiento de los conocimientos iniciales, en el favorecimiento de reflexiones ante las observaciones, en la participación del estudiante ciego en los procedimientos experimentales y en la promoción de debates.

Palabras clave: Experimentación. Ciego y videntes. Enseñanza de Ciencias de la Naturaleza.
*Doutoranda no Programa de Pós-Graduação em Educação Científica e Tecnológica da Universidade Federal de Santa Catarina (UFSC). Florianópolis, SC - Brasil. E-mail:<beatrizbiagini@gmail.com>.

**Doutor em Educação Científica e Tecnológica pela UFSC. Professor no Departamento de Química e no Programa de Pós-graduação em Educação Científica e Tecnológica da UFSC. Florianópolis, SC - Brasil. E-mail:<fabio.pg@ufsc.br>. 
EXPERIMENTAL ACTIVITIES IN THE EARLY YEARS OF ELEMENTARY SCHOOL: ANALYSIS ON A BACKDROP WITH BLIND STUDENTS

ABSTRACT: The research's purpose is to investigate limits and potentialities of an experimental activities methodology for teaching and learning in Natural Science in a class of 3rd-year elementary school attended by seers and one blind student. The proposal was based on literature discussions. The sources of information for qualitative analysis were video recordings of lessons and written records of students. The information analysis, guided by procedures of Discursive Textual Analysis, has identified potentialities for group work learning and explicitness of the students' knowledge on the subjects under study. There were limits on the questioning of the initial knowledge in favor of reflections on the remarks, the participation of the blind student in experimental procedures and promotion of debates.

KEYWORDS: Experimentation. Blind and sighted. Science teaching. 


\section{INTRODUÇÃO}

As políticas educacionais têm se articulado para garantir aos estudantes com as chamadas "deficiências" ", transtornos globais do desenvolvimento e altas habilidades o direito de estudar nas mesmas escolas e turmas daqueles que não possuem essas características, sem que suas diferenciações de ordem orgânica, cognitiva ou psíquica sejam tomadas como critério de segregação (BRASIL, 2007). Em consequência, entre os anos 2004 e 2014 houve elevação de 257,7\% nas matrículas de alunos da educação especial em turmas comuns (BRASIL, 2004; 2014). Entre esses alunos estão os cegos.

Por meio de pesquisas que tratam do estado da arte na área de ensino de Ciências da Natureza - a exemplo daquelas de Francisco e Queiroz (2008), Megid Neto e Rocha (2010) e Slongo e Delizoicov (2006) - tem-se indicativos de que o ensino de Ciências da Natureza para cegos nos anos iniciais do ensino fundamental é um tema de investigação incipiente, uma vez que essas pesquisas silenciam a respeito do assunto em seus resultados. Silva, Gonçalves e Marques (2015), também sinalizam a carência de trabalhos concernentes ao ensino de Ciências da Natureza para estudantes cegos nos anos iniciais do ensino fundamental e argumentam sobre a necessidade de se tornarem mais expressivos.

Revisões de literatura que tratam especificamente do ensino de Ciências da Natureza para cegos - como as de Santos et al. (2011) e Schwahn e Neto (2009) - indicam que existem trabalhos no âmbito do ensino médio, nos quais se destaca a preocupação com a produção de recursos didáticos, tais como modelos tridimensionais para observações táteis.

Admite-se que a construção de materiais didáticos adequados a estudantes cegos é uma demanda importante. No entanto, os obstáculos vivenciados por esses sujeitos nos processos de ensino e aprendizagem não se limitam à dimensão material. Isso está em acordo com a investigação desenvolvida por Camargo (2012) sobre a participação de cegos em aulas de Física. O autor identificou a comunicação como a principal geradora de dificuldades. Os videntes recorrem amplamente a referenciais visuais em sua forma de se comunicar, por exemplo, quando se reportam a um objeto através de expressões como "isso aqui" ou "aquilo ali". Outro obstáculo apontado foi a criação de espaços de segregação em aula: quando o atendimento é particularizado de tal modo que passa a haver uma aula para os videntes e outra para o cego.

Para além da superação dos desafios que tangem à infraestrutura física é necessário investir na formação docente e na construção de práticas educativas que favoreçam a aprendizagem de todos. Isso implica considerar os cegos e os videntes em interação, enfrentar as dificuldades de comunicação e construir metodologias de ensino. Camargo (2012) sinalizou a experimentação como uma possível favorecedora do processo de ensino e aprendizagem de estudantes cegos. Todavia, é importante considerar qual orientação metodológica dar à atividade para que contribua mais efetivamente ao processo de ensino e aprendizagem. Para certos docentes a realização de observações pode ser um dos objetivos dos experimentos, mas certificar-se de que todos os estudantes possam realizá-las não deve ser a única preocupação. Pois não há relação direta entre observar e aprender, e a experimentação não é uma promotora incondicional da aprendizagem discente (GONÇALVES, 2005). 
Nessa direção, existem trabalhos envolvendo a experimentação e participação de cegos com considerações metodológicas. Entretanto, poucos parecem ser esses exemplares, dentre os quais podemos destacar os de Camargo (2005), Evangelista (2008), Supalo (2005), Ferreira (2009) e Gonçalves et al. (2013). Cumpre registrar que nenhum desses se destina aos anos iniciais do ensino fundamental.

Face ao exposto, desenvolvemos uma pesquisa que teve como objetivo investigar limites e potencialidades de uma proposta de experimentação para o ensino e aprendizagem em Ciências da Natureza em um coletivo formado por um aluno cego e videntes nos anos iniciais do ensino fundamental.

\section{AS BASES TEÓRICO-METODOLÓGICAS DE UMA PROPOSTA DE EXPERIMENTAÇÃO PARA ESTUDANTES CEGOS E VIDENTES}

Há uma variedade de propostas para a experimentação no ensino de Ciências da Natureza, dentre as quais consideramos como possíveis contribuições a esta pesquisa os experimentos investigativos (GIL-PÉREZ; VALDÉS, 1996), a estratégia prediga-observe-explique (GUNSTONE, 1991), a experimentação problematizadora (FRANCISCO JÚNIOR; FERREIRA; HARTWIG, 2008), a experimentação sustentada nos princípios do educar pela pesquisa (GONÇALVES, 2005). Embora cada qual possua suas peculiaridades, há características recorrentes nessas propostas que podem contribuir à experimentação em coletivos como o que investigamos. Além disso, ponderamos estudos relacionados ao ensino de Ciências da Natureza para cegos (CAMARGO, 2005; FERREIRA, 2009; SOLER, 1999) e ao trabalho em grupo (BONALS, 2003).

Tomemos os conhecimentos iniciais dos discentes como primeiro centro de atenção. Tais conhecimentos são valorizados nos trabalhos sobre atividades experimentais supracitados, com a compreensão de que as afirmações feitas sobre aquilo que observamos são pautadas por conhecimentos que já possuímos e que nos permitem interpretações. Entre alguns professores, no entanto, persiste o entendimento de que os estudantes deveriam se comportar como tábulas rasas durante a realização dos experimentos. Julgam-nos promotores incondicionais da aprendizagem por seu suposto poder de tornar a "teoria palpável", comprovar teorias, fazer o aluno "ver para crer" (GONÇALVES, 2005). Mas “ver” não é suficiente para acreditar, tampouco para aprender novos conhecimentos.

Ademais, a atenção aos conhecimentos iniciais é importante para provocar o reconhecimento de seus limites pelos próprios estudantes e, assim, o desejo por conhecer melhor sobre o assunto em discussão (DELIZOICOV; ANGOTTI; PERNAMBUCO, 2002). Por isso, as propostas citadas inicialmente se caracterizam por discussões que permitam a explicitação das visões de mundo dos estudantes e o surgimento de questões que o conhecimento discente não dá conta de responder, fomentando a busca por novos conhecimentos.

Existem várias formas de se trabalhar com questões em sala de aula, bem como distintas compreensões sobre a natureza de uma questão estimuladora da procura pelo conhecimento. Por exemplo, nos três momentos pedagógicos (DELIZOICOV; ANGOTTI; PERNAMBUCO, 2002), aos quais a proposta de experimentação problematizadora mencionada (FRANCISCO JÚNIOR; FERREIRA; HARTWIG, 
2008) está articulada, são exploradas situações problemáticas do contexto social dos estudantes com o objetivo de fomentar a busca por conhecimentos que favoreçam a transformação da realidade. Há também propostas que partem de questões mais diretamente relacionadas aos fenômenos em estudo e centradas nos conceitos científicos (GIL-PÉREZ; VALDÉS, 1996). Seja como for há uma tendência em trabalhar com experimentos a partir de "questionamentos".

Do mesmo modo, há uma tendência em valorizar a comunicação entre os alunos na análise dos resultados experimentais. Ao socializarem os resultados de seu trabalho com restante da turma e com o professor, submetem suas conclusões à crítica e as divergências em relação às conclusões de outros alunos podem ser debatidas. As intervenções docentes podem favorecer o debate, o reconhecimento de inconsistências e o contraste com conhecimentos cientificamente reconhecidos.

Em relação à participação de cegos, as propostas de experimentação parecem ser escassas, mas existe uma aproximação com a discussão que apresentamos até aqui, com atenção aos conhecimentos iniciais discentes, à dimensão social da construção dos conhecimentos, à cooperação, ao trabalho em grupo e à resolução de problemas (CAMARGO, 2005; EVANGELISTA, 2008; FERREIRA, 2009; GONÇALVES et al., 2013). Além disso, caracterizam-se pela multissensorialidade, ou seja, pela possibilidade de interação com o experimento a partir de múltiplos sentidos.

Camargo (2005), por exemplo, desenvolveu uma proposta de experimento para o ensino de Física a cegos e indivíduos com baixa visão. Os discentes trabalharam em pequenos grupos, interagiram com situações experimentais através do tato e da audição e elaboraram hipóteses para resolução de problemas, as quais foram confrontadas entre si e com as explicações sistematizadas. Outra pesquisadora, Ferreira (2009), trabalhou com uma turma dos anos finais do ensino fundamental, formada por videntes e uma cega, propondo a resolução de problemas através de grupos de trabalho colaborativo. Os discentes formularam problemas e hipóteses, planejaram investigações, previram e avaliaram resultados experimentais. Houve favorecimento do debate de ideias e reflexões na resolução dos problemas, contribuindo para a construção de conhecimentos. A estudante cega participou ativamente das atividades. A proposta também contribuiu para aprendizagens atitudinais ao favorecer interações socioafetivas, manifestação de afetividades, cuidado e interajuda.

Nos trabalhos de Camargo (2005) e Ferreira (2009) foram oferecidas condições materiais de participação aos estudantes cegos. Roteiros em braile, esquemas em relevo, máquina perkins, por exemplo, foram disponibilizados. As atividades foram planejadas de modo que os procedimentos e as observações pudessem ser realizados por todos os estudantes. Desse modo, além da visão, o tato, a audição, paladar e olfato puderam ser explorados nas atividades - ao que se tem denominado por multissensorialidade (SOLER, 1999).

A habilidade de explorar os ambientes, objetos e fenômenos através dos diferentes sentidos não é algo espontâneo, mas resultado de um processo educativo (SOLER, 1999). Aos cegos, em particular, o sentido do tato é de grande importância, mas para Vygotski (1997) eles não apresentam naturalmente um tato superdesenvolvido como se costuma supor. A habilidade de perceber através dos 
sentidos remanescentes pode ser maior ou menor de acordo com as vivências do indivíduo. Do mesmo modo que as habilidades perceptivas, o desenvolvimento em outros âmbitos, como o cognitivo e social, também depende de contextos estimulantes e não é consequência direta da ausência de visão (FRANÇAFREITAS; GIL, 2012).

As ponderações sobre o desenvolvimento das habilidades perceptivas implicam no reconhecimento de que não basta proporcionar oportunidades de observação para que o aluno cego obtenha informações em quantidade e qualidade desejáveis. É possível que ele não tenha autonomia para realizar as observações propostas e será necessário orientá-lo nessas atividades. Igualmente é preciso ter o cuidado de que as experiências sensitivas não sejam negativas, pois nem todas as sensações são agradáveis e isso deve ser considerado para que a atividade não traga desconforto (SOLER, 1999).

Por fim, vamos considerar o trabalho em grupo. Nas diferentes propostas de experimentos citadas há a compreensão de que a construção de conhecimentos - conceituais, atitudinais ou procedimentais - depende de interações sociais e valoriza-se o potencial dos grupos. Mas agrupar estudantes e atribuir-lhes uma tarefa comum não é o bastante para que ela seja assumida por todos e que existam interações favorecedoras da aprendizagem. É comum apenas parte do grupo trabalhar ou realizar as tarefas sem discussões. Esses problemas podem ser enfrentados quando o trabalho em grupo é reconhecido como objeto de ensino. Nesse sentido, Bonals (2003) expõe que o trabalho em grupo envolve:

[...] a capacidade de chegar a acordos baseados em diálogo, de facilitar a comunicação, de favorecer as conveniências de todos, o que seguramente passa pela capacidade de incluir todos os integrantes, gratificá-los, fazer com que se sintam bem durante os processos de trabalho, ajudá-los adequadamente, etc. E, como já dissemos, também a capacidade de ser um membro ativo, de participar, de ser querido pelos colegas, de pedir ajuda quando necessário, etc. (BONALS, 2003, p. 13-14).

Para favorecer a aprendizagem dos conhecimentos citados, Bonals (2003) propõe aos professores que: orientem a formação dos grupos, estabelecendo critérios de acordo com os objetivos da atividade; tenham atenção à dinâmica de trabalho, com intervenções frequentes no sentido de resolver atritos, avaliar o equilíbrio participativo e decisório, favorecer as interações; explicitem aos alunos que a cooperação é um dos objetivos de seu trabalho e que essa seja tomada como objeto de avaliação.

Com base na literatura, identificamos elementos sinalizados com frequência como relevantes às atividades experimentais, tais como a consideração dos conhecimentos prévios dos estudantes sobre os objetos de estudo, as discussões sobre esses conhecimentos entre os alunos e contrastes com a realidade empírica, e a compreensão dos questionamentos como favorecedores da busca por conhecimentos. O trabalho em grupo, a comunicação e a multissensorialidade também foram apontados como importantes aos experimentos. Consideramos que tais aspectos podem trazer contribuições às atividades experimentais com alunos cegos e videntes. 


\section{PROPOSTA DE EXPERIMENTAC̣ÃO E ENCAMINHAMENTOS METODOLÓGICOS}

Inspirados na discussão exposta, elaboramos uma proposta de experimentação para uma turma (29 alunos) do $3^{\circ}$ ano do ensino fundamental de uma escola da rede pública, com a participação de videntes e um cego. Desenvolvemos três atividades experimentais ao longo de quatro encontros — cada encontro com média de 78 minutos. Os responsáveis pelos alunos autorizaram sua participação mediante Termo de Consentimento Livre e Esclarecido. Acrescentase que a pesquisa foi aprovada pelo comitê de ética da instituição. A primeira autora deste artigo lecionou as aulas com a colaboração da professora da turma.

Realizamos um estudo piloto na turma, através do qual nos aproximamos do coletivo investigado e reconhecemos parte de suas demandas. A proposta aqui apresentada é resultado da interlocução com a literatura e do estudo piloto.

De acordo com informações preliminares, a turma não possuía o hábito de trabalhar em grupo. Para favorecer a aprendizagem do trabalho em grupo a turma foi organizada em grupos de quatro alunos e cada membro recebeu uma atribuição, como segue: leitor (lê os materiais em voz alta aos colegas do grupo); escriba (faz registros); comunicador (porta-voz do grupo nos momentos de socialização); coordenador (organiza o trabalho no grupo e orienta os colegas na manipulação dos materiais). A opção pela atribuição de funções está presente em outras investigações (SILVA, 2008; BONALS, 2003) como forma de favorecer o equilíbrio participativo. Há autores que trabalham com a circulação das funções a cada atividade. Preferimos trabalhar com funções fixas na sequência de três experimentos para favorecer que cada estudante desenvolvesse as habilidades relacionadas à sua função.

As atividades experimentais foram organizadas em três etapas. A etapa inicial teve como objetivo favorecer a explicitação dos conhecimentos iniciais dos estudantes e o reconhecimento de seus limites. Em um primeiro momento apresentamos perguntas para que respondessem individualmente e por escrito e em seguida solicitamos que elaborassem uma resposta coletiva no pequeno grupo a partir da discussão sobre as ideias individuais. A solicitação de respostas individuais antes do debate no pequeno grupo teve a intenção de favorecer que todos explicitassem suas ideias, o que não aconteceu no estudo piloto (quando não apresentamos as questões individualmente). Uma vez elaboradas as respostas dos pequenos grupos, cada comunicador as apresentava ao grande grupo. Nesse momento o professor provocou discussões entre todos os estudantes, fez novas perguntas desafiando-os a justificarem suas respostas e também apresentar novas situações, as quais os conhecimentos explicitados fossem insuficientes para explicar. Nessa etapa coube ao coordenador organizar o trabalho do grupo, certificar-se que as ideias foram explicitadas na resposta coletiva e mediar nas divergências de ideias. O leitor foi o responsável por ler questionamentos ao grupo e o escriba por registrar as respostas.

Os procedimentos experimentais, observações e análise dos resultados foram realizados na segunda etapa dos experimentos, quando se buscou por informações que contribuíssem à reflexão e evolução dos conhecimentos iniciais, permitindo ampliar as compreensões sobre os assuntos estudados. A organização 
das informações obtidas pelos alunos foi realizada através de registro escrito das observações e resolução de questões a partir de discussões no pequeno grupo, com a mediação docente quando necessária. O coordenador ficou responsável por receber os materiais experimentais e distribuí-los no grupo, por dividir o trabalho para que todos participassem da montagem dos experimentos e resolver possíveis conflitos. O leitor foi o responsável por ler o roteiro experimental e as questões para discussão no grupo (embora cada membro tivesse à sua disposição uma cópia do material). O escriba ficou incumbido de registrar as respostas discutidas.

A etapa final consistiu na comunicação dos resultados de cada pequeno grupo ao restante da turma, tarefa atribuída ao comunicador. Os demais estudantes atuaram nessa etapa participando da discussão orientada pela professora. Nessa discussão se esperava que as diferentes conclusões apresentadas fossem contrastadas e questionadas no intuito de identificar suas possíveis limitações e organizar os conhecimentos elaborados no decorrer da atividade.

A multissensorialidade foi característica de todas as etapas das atividades experimentais (SOLER, 1999) - possibilitando observações táteis, olfativas, auditivas e visuais. Os materiais foram impressos em tinta com uma versão em braile para o estudante cego (alfabetizado em braile), que também necessitou de uma máquina perkins. As ilustrações presentes nos roteiros em tinta tiveram uma versão em relevo. Os experimentos foram planejados de modo que as observações pudessem ser feitas através do tato, olfato, audição e visão (no caso dos videntes).

Com tal forma de trabalhar com atividades experimentais pretendemos favorecer a aprendizagem de conhecimentos das Ciências da Natureza e do trabalho em pequenos grupos, que, por sua vez, envolve aprendizagens associadas à cooperação, à solidariedade e ao respeito às diferenças.

A decisão pelos conhecimentos das Ciências da Natureza a serem tratados nas atividades pautou-se em discussões com a professora, que, considerando seu plano de ensino sinalizou questões relacionadas à "água" como possibilidades às intervenções. Os experimentos abordaram os assuntos: importância da água para os vegetais, potabilidade e tratamento de água.

O primeiro experimento consistiu na submissão de sementes de feijão a duas condições distintas: em algodão seco e em algodão umedecido. Cada amostra foi colocada em um pote, posteriormente fechado com plástico transparente e abrigado em local iluminado. Após uma semana os alunos analisaram o material e identificaram transformações em alguns dos conteúdos dos potes - aqueles em que as sementes foram alocadas em algodão umedecido. A atividade teve como objetivo explorar a importância da água para o desenvolvimento dos vegetais.

Com o objetivo de apreender e discutir os conhecimentos discentes sobre quais critérios usar para avaliar a potabilidade de um líquido, foi realizada a segunda atividade experimental. $\mathrm{Na}$ etapa procedimental apresentamos garrafas com líquidos não identificados e questionamos os discentes sobre a possibilidade de ingeri-los. As respostas apresentadas constituíram objeto de análise e discussão de critérios para avaliação da potabilidade de um líquido.

$\mathrm{Na}$ última atividade experimental foi estudada uma das etapas do tratamento de água: a filtração. O experimento consistiu na fabricação de um filtro com areia e pedras, análogo aos filtros usados em estações de tratamento. Em 
seguida, os estudantes filtraram uma mistura de água, terra e folhas e puderam reconhecer transformações no aspecto do material, bem como discutir novas intervenções que deveriam ser feitas a fim de garantir sua potabilidade.

Em diferentes momentos foram apresentadas questões aos estudantes, para que respondessem a partir de discussões nos grupos. A resposta coletiva de cada grupo deveria expressar a síntese das ideias dos alunos e expor eventuais desacordos nas conclusões em relação aos questionamentos.

Os registros individuais ou coletivos dos alunos em resposta às questões constituíram parte de nosso material para análise da proposta. Além disso, obtivemos informações através de videogravações de período integral do desenvolvimento dos 3 experimentos - 311 minutos distribuídos ao longo de 4 encontros, cuja transcrição fundamentou-se nas convenções indicadas por Carvalho (2006). A coleta de informações centrou-se em um grupo de 4 estudantes: Joana (leitora), Maria (escriba), Tadeu (comunicador) e João (coordenador), sendo os três primeiros videntes e o último cego. Também aparecem nas transcrições falas de estudantes de outros grupos (em interações com o grupo investigado), da professora pesquisadora (identificada como P. P.) e da professora da turma (identificada como P. Ana). A professora pesquisadora assumiu a regência da turma com a colaboração da professora da turma. Todos os nomes são fictícios.

Os textos que constituíram nosso corpus (registros dos alunos e transcrições das videogravações) foram submetidos à Análise Textual Discursiva (MORAES; GALIAZZI, 2013) com o processo de desmontagem, categorização e construção de textos analíticos. As categorias que emergiram da análise e que serão discutidas adiante são: o trabalho cooperativo no pequeno grupo e os experimentos; dificuldades no trabalho em grupo articulado às atividades experimentais; a dimensão concreta dos experimentos; o ensino e a aprendizagem de conhecimentos de Ciências da Natureza por meio da experimentação.

\section{O TRABALHO COOPERATIVO NO PEQUENO GRUPO E OS EXPERIMENTOS}

A cooperação existe quando os membros de um grupo trabalham com objetivos comuns, entendendo o sucesso coletivo como sucesso pessoal, e isso não é garantido com o mero agrupamento de estudantes (BONALS, 2003; JOHNSON; JOHNSON; HOLUBEC, 1999). Durante as aulas os alunos cooperaram em alguns aspectos das atividades, os quais não foram apresentados explicitamente como tarefas. Foram eles: os procedimentos experimentais, o favorecimento da participação de João e a comunicação de Tadeu.

Os procedimentos procedimentais mobilizaram especialmente Joana, Tadeu e Maria, que se organizaram para que todos participassem:

Maria: - vai... lê de novo... Joana...

Joana: - nos copos de número par... nos copos de número par... copo de número par... vou fazer o 6 e o... (Joana começa a pegar os copos e verificar a legenda))

Maria: - tu vai fazer esse... ((entrega para Tadeu um dos copos)) 


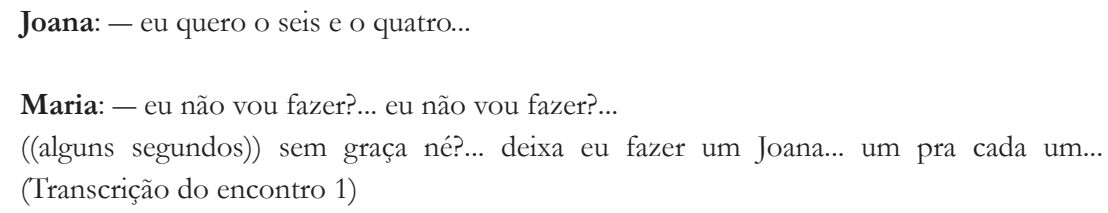

Houve preocupação pela compreensão das orientações, divisão do trabalho e também pela resolução de conflitos - quando Maria percebeu que trabalharia menos que os colegas a questão foi resolvida rapidamente sem que o problema se ampliasse. Cabe ressaltar o papel determinante de Maria na organização do grupo, assumindo uma postura de liderança. Todavia, a função de coordenador havia sido atribuída a outro estudante, João, que emitiu indicativos de dificuldade em desempenhá-la.

A disposição de Tadeu, Joana e Maria em realizar os procedimentos experimentais parece relacionar-se ao interesse que tiveram na dimensão concreta dos experimentos e não, necessariamente, em um comprometimento com a atividade de modo mais amplo. Como discutiremos em outra categoria, o interesse limitado à dimensão concreta pode constituir-se em um obstáculo à aprendizagem conceitual. De todo modo, o fato de os alunos convergirem esforços para realizar os procedimentos pode ter contribuído a aprendizagens importantes, como a capacidade de: favorecer a participação de todos, reconhecer e respeitar as necessidades dos colegas, ser um membro ativo, ajudar e pedir ajuda quando necessário (BONALS, 2003).

$\mathrm{O}$ interesse nos procedimentos experimentais parece não ter sido compartilhado por João. Sua participação foi uma preocupação constante dos colegas, sendo assumida por eles como uma tarefa:

Maria: - quer fazer um João?...

João: - não... não sei fazer... não sou muito chegado em algodão...

((Maria pega um dos potes coloca um chumaço de algodão na extremidade - sem afundar - depois estende o copo para João))

Maria: - ó... afunda agora o algodão aqui dentro desse copinho aqui... ó... afunda...

((João pressiona o chumaço de algodão)) aí... aí... deu...

(Transcrição do encontro 1)

O comportamento dos estudantes pode estar relacionado a uma dinâmica cotidiana na turma. João era frequentemente "assessorado" por seus colegas. Por exemplo, todos os dias um deles era sorteado pela professora para acompanhar João durante o recreio. No entanto, a atitude de solidariedade dos colegas acompanhava um problema: pouco espaço ao desenvolvimento da autonomia de João. Mesmo que as atividades tenham sido planejadas considerando a sua presença e com o cuidado para que tivesse plenas condições de participação, ele participava apenas em resposta às intervenções dos colegas e professoras. 
Talvez a mais importante conquista do grupo tenha sido a forma como os estudantes interagiram em função da comunicação a ser realizada por Tadeu. Ele era o responsável por socializar para o restante da turma as conclusões do grupo em relação aos questionamentos que lhes foram apresentados durante as atividades. Tadeu tinha dificuldades em expressar-se oralmente e também na leitura - habilidades importantes na tarefa do comunicador. O sucesso na comunicação de Tadeu foi entendido como o sucesso de todo o grupo. Com isso criou-se uma situação de interdependência positiva - na qual o sucesso de um indivíduo depende do sucesso de todos, uma das condições para o trabalho cooperativo (JOHNSON; JOHNSON; HOLUBEC, 1999).

Uma alternativa às dificuldades de Tadeu foi sinalizada por Joana no primeiro encontro da pesquisa: "ô prof... se ele não sabe ler um pouco ele já tem... ele tem outra coisa pra fazer... ele ouve a resposta e depois fala... ele não sabe falar?... sabe...". Ainda nesse encontro, Maria propõe auxílio: "tu sabe ler Tadeu?... é (possível?)... agora eu posso ler pra ti...”. E, no terceiro encontro, João também manifesta preocupação momentos antes de Tadeu desempenhar sua função de comunicador diante da turma: "vou até abaixar meu som da música..." - referindose, provavelmente, aos sons que fazia com frequência (percussão vocal, solfejos).

Quem assumiu de modo mais intenso o cuidado com a preparação para as comunicações foi Joana, coerentemente com sua função de leitora. Mas o modo como se deu a preparação foi problemático, pois incentivava a mera repetição de Tadeu:

$$
\begin{aligned}
& \text { Joana: }-\operatorname{sim} . . \text { porque é chá... } \\
& \text { Tadeu: }-\operatorname{sim} . . . \text { porque é chá... } \\
& \text { Joana: }-\operatorname{sim} . . \text { porque é chá... } \\
& \text { Tadeu: }-\operatorname{sim} . . \text { porque é chá... } \\
& \text { Joana: }-\operatorname{sim} . . . \text { porque é chá... } \\
& \text { Tadeu: }- \text { sim... porque é chá... } \\
& \text { (Transcrição do encontro } 3 \text { ) }
\end{aligned}
$$

A necessidade de memorizar as respostas pode relacionar-se a problemas no modo como elas foram construídas, o que será objeto de análise na próxima categoria. Por enquanto a análise permite identificar que a proposta favoreceu as interações no grupo, tornando possível emergir aspectos que foram assumidos cooperativamente - ainda que os estudantes não tenham contribuído de igual maneira.

Com isso, a proposta tornou-se um espaço favorecedor de aprendizagens atitudinais, tais como o respeito, a cooperação e a solidariedade. Ademais, os estudantes puderam fortalecer e desenvolver habilidades relacionadas ao trabalho em grupo quando, por exemplo, dividiram o trabalho para a realização das tarefas, resolveram problemas de relacionamento interpessoal, reconheceram as dificuldades dos colegas e ofereceram auxílio. 


\section{DIFICULDADESNOTRABALHOEM GRUPO ARTICULADO ÀS ATIVIDADESEXPERIMENTAIS}

Nem todas as tarefas foram assumidas como responsabilidade grupal. O desenvolvimento das atividades foi permeado por dificuldades relacionadas a atitudes dos estudantes, à forma como compreenderam as tarefas que lhes foram apresentadas e, provavelmente, a conhecimentos que possuíam sobre como trabalhar em grupo.

Uma das dificuldades foi alcançar equilíbrio entre os membros na participação e na tomada de decisão, algo que é um dos mais importantes desafios do trabalho em grupo (BONALS, 2003). Embora tenham ocorrido conquistas como as discutidas na primeira categoria, o mesmo não se deu na atividade como um todo.

A atribuição de funções aos membros do grupo trouxe resultados positivos para a participação de Tadeu. No entanto, não implicou que os estudantes assumissem necessariamente aquelas que lhes foram atribuídas. João, definido como coordenador, chega a rechaçar a sua função: " - ah... eu não quero ser coordenador... eu sempre fui...”. (Transcrição do encontro 4). Ressalta-se que, no primeiro encontro, ele mesmo se candidatou a tal função. $\mathrm{O}$ aluno, de modo geral, envolveu-se superficialmente nas atividades:

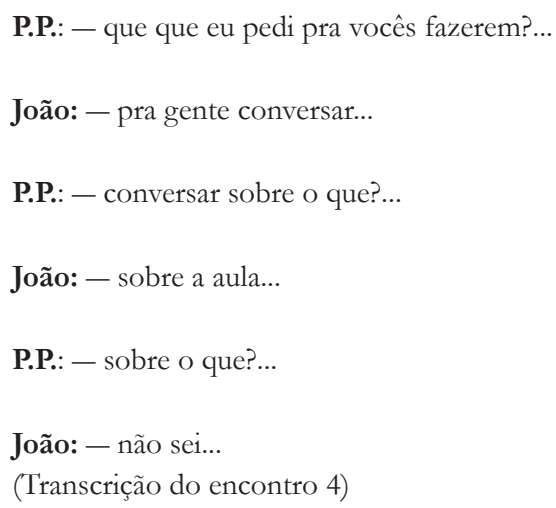

Há diversas possibilidades de intervenção diante de situações em que nem todos os membros de um grupo trabalham (BONALS, 2003). Uma delas é dirigir-se diretamente ao estudante que não trabalha, questionando-o sobre suas dificuldades e responsabilidades, como fez a professora-pesquisadora. Outra é chamar a atenção de todo o grupo para o fato de que a participação equilibrada é algo que precisam aprimorar e propor que considerem formas de resolver os problemas. Desse modo, solucionar o desequilíbrio passa a ser uma responsabilidade do grupo e não apenas do aluno que não participa. Enfrentar esses problemas pode favorecer aprendizagens sobre como se relacionar, resolver conflitos, reconhecer as necessidades dos colegas e ser solidário.

A coordenação do grupo foi assumida espontaneamente por Maria, que, de certo modo, trouxe contribuições ao tentar favorecer as interações e a participação de todos e, de outro, centrou em si a tomada de decisões: 


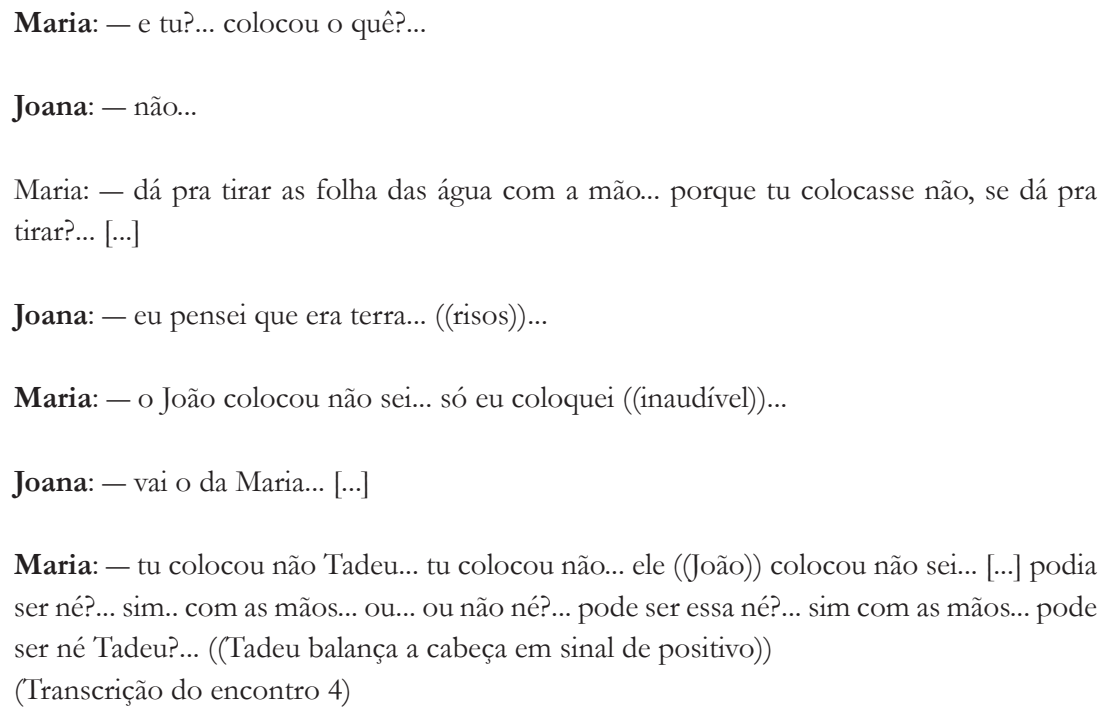

No trecho reconhecemos o empenho para que fossem explicitadas todas as respostas individuais à pergunta "é possível separar terra e folhas de água? Como?". Mas, as diferenças nas respostas individuais não foram analisadas. Embora os demais não tivessem inicialmente pensado como Maria, a decisão foi usar a sua resposta para representar o grupo. Isso se relaciona à posição de liderança que ocupava, cristalizada durante os três experimentos. Provocar a ruptura no modo como os estudantes interagem e a circulação dos papéis ocupados por seus membros pode ser fundamental para a qualidade do trabalho no grupo (SILVA, 2008).

A forma como tomaram decisões pode estar relacionada aos conhecimentos discentes sobre o trabalho em grupo. Pareceram ter dificuldades para examinar as divergências, questionar, argumentar e explicar seus pontos de vista. No exemplo supracitado, Joana considerou a presença de terra na mistura e por isso afirmou que não era possível fazer a separação. Maria parece ter ignorado a terra e, pensando apenas na folha, afirmou ser possível fazer a separação com as mãos. O que, de fato, é possível no caso da folha, mas não da terra.

Reconhecendo que os membros de um grupo assumem papéis espontaneamente e entendendo a estagnação dos papéis como algo problemático, Silva (2008) trabalhou com a atribuição de funções e fez com que fossem trocadas a cada atividade. Isso favoreceu a circulação de papéis no grupo e contribuiu para o equilíbrio na participação. Tal possibilidade merece ser considerada em nossa proposta de experimentação, já que a atribuição de funções fixas relacionou-se a dificuldades para o equilíbrio na participação e na tomada de decisões — ainda que se reconheça que as funções fixas também tenham contribuído, especialmente no que se refere aos resultados do desempenho da função de comunicador, como se destacou na categoria anterior.

Outro aspecto problemático foi a atitude pouco otimista em relação a Tadeu:

Joana: - botaram água no um... (não lembra?)... botaram água no um... 
(Joana pega um dos potes, sem abrir, olha e fala com Tadeu. Ela está séria. Entrega para Maria que olha para o pote, olha para Tadeu, coloca a mão na cabeça e dá um sorriso))

Tadeu: - deixa eu ver... não fui eu não...

Maria: - deixa eu ver esse...

Tadeu: - (de certo) foi a professora que...

((risos das meninas e fala incompreensível))

Tadeu: - não fui eu... sério...

(Transcrição do encontro 2)

Os estudantes parecem não compreender o problema como uma responsabilidade grupal, tampouco a irrelevância da identificação de um "culpado". O problema identificado é imposto à responsabilidade de Tadeu, ainda que ele a negasse. $\mathrm{O}$ acontecimento relaciona-se à perspectiva manifestada em outros momentos de que Tadeu seria menos "habilidoso" que os colegas, em particular na leitura e na escrita. A desconstrução dessa forma de perceber o colega pode se dar na medida em que as atividades favoreçam que ele explicite suas potencialidades. A função de comunicador trouxe contribuições nesse sentido, pois favoreceu as interações no grupo e fez com que Tadeu demonstrasse que também poderia contribuir. Ele passou a interagir mais intensamente com os colegas e mostrou maior segurança na comunicação e inclusive nas discussões sobre os questionamentos apresentados ao grupo:

Maria: - vinagre... o que que o vinagre faz mesmo?...

Tadeu: - coloca que vai na salada...

((Maria olha para Tadeu com expressão de contentamento com a sugestão))

(Transcrição do encontro 3)

Por outro lado, as dificuldades na interação com Tadeu podem derivar de conhecimentos dos seus colegas sobre como agir em grupo e de fragilidades em atitudes como o respeito e solidariedade. Embora tenham sido manifestadas em alguns momentos, sobretudo no modo como cooperaram para que ele se preparasse para a comunicação, são atitudes que precisam ser fortalecidas.

Em síntese, foi possível identificar conhecimentos discentes sobre o trabalho em grupo, os quais merecem maior atenção: decisões protagonizadas por apenas uma estudante; dificuldade em socializar ideias individuais e discutilas; dificuldades em resolver conflitos; pouco envolvimento de um estudante. Ao mesmo tempo em que permitiu a explicitação desses conhecimentos, o trabalho em grupo se constituiu em um espaço favorecedor da transformação de atitudes e perspectivas, certamente sem negar o caráter processual e moroso das aprendizagens atitudinais. 


\section{A DIMENSÃO CONCRETA DOS EXPERIMENTOS}

Para parte dos estudantes as observações e procedimentos experimentais tornaram-se o principal centro de interesse ao longo das atividades, havendo dificuldades na promoção de questionamentos e reflexões para além do concreto. Por outro lado, um dos estudantes não manifestou interesse semelhante ao de seus colegas, tampouco empreendeu essas tarefas com autonomia, sendo necessária uma mediação constante para que se envolvesse nos procedimentos. Em um ou outro caso, a dimensão concreta dos experimentos repercutiu em obstáculos.

Joana, Maria e Tadeu explicitaram certo entusiasmo diante dos procedimentos experimentais e observações. Joana no segundo encontro explicitou: "mostra pro Carlos... cheira... mostra pra Gabi... faz ela cheirar... [...] Gabi... Gabi... cheira aqui... cheira... ((risos))". Com um broto de feijão nas mãos, resultado de um dos experimentos, empolga-se e quer que os colegas de outro grupo vejam e cheirem.

Algo semelhante aconteceu em outros momentos, como no anseio das alunas em refazer um dos experimentos em suas casas:

Joana: - será que dá pra fazer em casa?...

Maria: - eu vou tentar...

Joana: - eu também... só que eu não sei (o que que vai)...

Maria: - algodão... areia fina... areia grossa e brita...

Joana: - eu vou pegar o papel ((roteiro)) pra ver... (Transcrição do encontro 4)

Não há, necessariamente, problemas na admiração pelos fenômenos observados. O problema é quando a atividade limita-se à admiração, à vontade de repetir o experimento, ao prazer estético - o que não garante a aprendizagem dos conhecimentos e pode representar, inclusive, um obstáculo. Para Bachelard (1996), diante desse problema previsível, o desafio é provocar a reflexão e o questionamento, o movimento do concreto ao abstrato.

Resultados inesperados podem representar a possibilidade para a revisão e reformulação das ideias iniciais. Uma oportunidade para isso aparece no trecho:

P.P.: - vocês não abriram todos... vamo abrir todos... ((P.P. abre os potes que ainda estão com o plástico))... lembram que vocês tinham colocado água em quatro?...

Maria: - só que... não... não cresceu ali...

P.P.: - nem todos cresceram... isso é uma coisa interessante também...

((Tadeu entrega para P.P. o broto de feijão que João acabou de lhe devolver))...

P.P.: - não sentiu?... então vamo pegar aqui... Tadeu... vamo ajudar ele ((o João))... (Transcrição do encontro 2) 
Maria refere-se ao não crescimento de um broto de feijão em um pote em que se previu que isso aconteceria. No entanto, a professora-pesquisadora parecia, naquele momento, preocupada em favorecer a interação de João com o concreto, o que se relaciona à dificuldade do aluno em realizar os procedimentos experimentais e observações. Em geral, os fez apenas quando seus colegas ou professoras o orientavam, sem explicitar interesse nas atividades:

P. Ana: - segura... a Joana botou água nessa seringa aqui ó... tá vendo que tá molhadinha a ponta... você vai apertar essa seringa e vai botar água dentro do copinho do feijão... tá bom?... vamo botar água pra molhar essa sementinha de feijão... aperta... ((neste primeiro trecho, Ana coloca a seringa na mão de João e depois manipula a seringa junto com ele, pressionando-a e fazendo a água escorrer)) isso... pronto... a água já tá aqui... vou botar o seu dedo pra você sentir... tá vendo?... que o feijãozinho tá molhado?... ((Ana coloca a mão de João sobre o algodão))

João: - uhum...

P.Ana: - (pronto)... tá vendo/... não... tá sentindo?...

João: - PUM... PUM... ((João toca na barriga de P. Ana e faz som onomatopaico de soco))... (Transcrição do encontro 1)

As atividades experimentais foram planejadas considerando que pudessem favorecer a participação dos estudantes (cego e videntes) com autonomia. O roteiro experimental foi escrito com detalhamento considerável e transcrito em braile. Também foram feitos esquemas da montagem dos experimentos em relevo. Ainda assim, João, manifestou pouca autonomia na realização das atividades, sem recorrer aos materiais impressos e roteiros, trabalhando apenas quando era orientado. Todavia há que se considerar que autonomia é algo a ser construído e que João ainda é uma criança. Além disso, a qualidade das observações táteis resulta de aprendizagens, não se trata de uma habilidade espontânea (OCHAITA; ROSA, 1995; SOLER, 1999). João, em geral, tocava brevemente o que lhe era apresentado:

P.P.: pega Tadeu... mostra pro João... Tadeu...

Tadeu: ó João... sente aí... só que não quebra hein?... ((Tadeu entrega um broto de feijão para João. João pega e tateia com uma mão por alguns segundos e devolve para Tadeu)) (Transcrição da aula 2)

O tato é um sentido que demanda exploração dos objetos para deles extrair informações, ou seja, uma atividade perceptiva autodirigida (ROSA; OCHAITA, 1995). Às vezes se pensa que os cegos possuem naturalmente um tato superdesenvolvido, mas isso demanda tempo e requer um trabalho sistemático de estimulação (FRANÇA-FREITAS; GIL, 2012; OCHAITA; ROSA, 1995). A postura de João durante as observações pode indicar necessidade de desenvolvimento de suas habilidades perceptivas. As atividades experimentais, ao mesmo tempo em que demandam essas habilidades, podem representar um espaço 
propício ao seu desenvolvimento. O trabalho colaborativo com um profissional habilitado em educação especial no planejamento dos experimentos pode trazer contribuições, pois ele tem conhecimentos mais amplos sobre estratégias de estimulação e pode conhecer o histórico de estimulação do estudante.

A proposta de experimento foi organizada para proporcionar a participação de todos, mas houve dificuldades nesse sentido. O estudante cego participou menos das atividades de manipulação e discussão. Em contrapartida, o envolvimento dos outros estudantes esteve associado à dimensão concreta e pitoresca da atividade - o que também representa um aspecto a ser enfrentado pela mediação docente.

\section{O ENSINO E A APRENDIZAGEM DE CONHECIMENTOS DE CIÊNCIAS DA NATUREZA POR MEIO DA EXPERIMENTAÇÃO}

Destacou-se nas atividades o modo como se deu a apreensão equestionamento dos conhecimentos iniciais dos estudantes por parte das professoras e o debate de ideias nos pequenos grupos, aspectos que receberam atenção especial na construção da proposta por sua importância no processo de ensino e aprendizagem.

Foi possível apreender sistematicamente os conhecimentos discentes. No primeiro experimento, sobre importância da água para os vegetais, as ideias manifestadas inicialmente pelos alunos aproximaram-se à registrada por Maria: "Os vegetais precisa da água para crescer e multiplicar". Com os resultados experimentais a ideia de "crescimento" foi confirmada. Embora não tenham sido evidenciados indicativos de enriquecimento nos conhecimentos iniciais, o experimento abriu espaço para questões como esta: “será que esse algodão tem nutrientes... além da água... os nutrientes que a planta precisa pra crescer forte saudável e bonita?...” (P.P., transcrição do encontro 2). Para respondê-la novos experimentos poderiam ter sido realizados. O experimento não precisa sempre trazer respostas, mas pode provocar o surgimento de perguntas. Houve contribuições nesse sentido, ainda que não tenha sido possível explorar os questionamentos que emergiram no âmbito da pesquisa.

$\mathrm{Na}$ segunda atividade experimental os questionamentos promoveram a explicitação de ideias contraditórias. Inicialmente foi solicitado que os alunos se posicionassem diante da questão: "É possível saber se um líquido pode ser bebido sem saber seu nome? Por quê?". E obtivemos respostas negativas, como neste registro de Maria: "Não porque pode ter algo dentro dela". A possibilidade de conter "veneno" também foi mencionada por Tadeu: "pode ter um veneno dentro...”. Na segunda etapa quando foram apresentados a uma situação real, com garrafas preenchidas com líquidos desconhecidos, imediatamente se colocaram a tentar "descobrir" o seu conteúdo a partir de observações visuais e/ou olfativas:

$$
\begin{aligned}
& \text { João: - abre aí... é água?... } \\
& \text { Joana: — a do Tadeu é limpinha... } \\
& \text { João: - ãh?... }
\end{aligned}
$$

Tadeu: - cheira pra ti ver... 
João: - abre...

Tadeu: - cheira pra ti ver o meu é álcool... o João...

Joana: - é vinagre...é vinagre... é vinagre... ((risos))

(Transcrição do encontro 3)

A contradição entre as afirmações iniciais e o comportamento dos estudantes permitiu que fossem sinalizadas as dificuldades em se avaliar a potabilidade da água através de observações diretas (utilização das propriedades organolépticas): "podia ter veneno em cada uma dessas garrafinhas... inclusive na de chá... podia ter um veneno... que não vai ter cheiro de nada" (P.P. na transcrição do encontro 3).

No último experimento, sobre tratamento de água, houve indicativos de aprendizagens sobre aspectos discutidos na atividade sobre potabilidade da água quando afirmaram que um líquido filtrado, embora estivesse límpido e sem cheiro, não poderia ser consumido "porque pode ter bactérias" (registro do grupo).

Reconhecemos que as evoluções nos conhecimentos iniciais precisam ser tomadas com parcimônia. Por exemplo, é preciso considerar a forma como os conhecimentos iniciais foram explorados nas ações docentes. Em outras palavras, embora a proposta tenha favorecido a explicitação desses conhecimentos e, em alguma medida, contribuído para o seu enriquecimento, o que é considerado uma potencialidade, houve limites na atuação docente quanto ao seu questionamento:

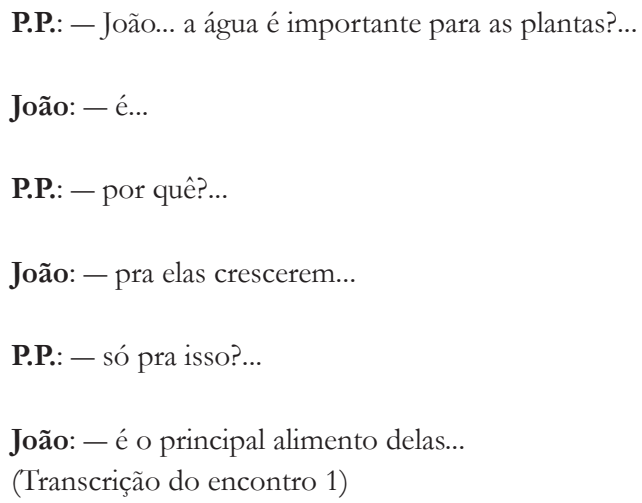

João manifesta a compreensão, bastante comum, de que a água é um alimento para a planta (CARNEIRO, 1999) - a qual precisa ser questionada, pois os vegetais produzem seu alimento através do processo de fotossíntese. Seria importante a continuidade do estudo com uma atividade em que se analisassem outras variáveis além da água (substrato e luminosidade, por exemplo).

Um dos limites identificados no decorrer das aulas diz respeito ao debate de ideias no pequeno grupo. Os alunos parecem ter entendido as solicitações docentes para discussão das questões apresentadas ao longo das atividades como uma demanda de consenso sobre as respostas: 
Joana: - a água é importante para os vegetais?... por quê?...

Maria: - os vegetais precisam da água para crescer e multiplicar... tá bom assim?... todo mundo concorda?... ((Tadeu e Joana confirmam com sinal gestual))... João... tu concorda?... essa resposta aqui... sim... os vegetais precisam da água para crescer e multiplicar... concorda?...

João: $-\operatorname{sim} .$.

Maria: - então é essa...

(Transcrição do encontro 1)

Embora exista empenho em cooperar para a elaboração dessas respostas, existem dificuldades em discutir, em expor e rever as ideias individuais. Elaborar uma resposta não deve implicar abrir mão de ideias, mas usá-las para enriquecer uma resposta coletiva, que, inclusive, contemple as divergências quando não for possível estabelecer um consenso.

Depreende-se da análise que a proposta de atividade experimental colaborou para promover a explicitação dos conhecimentos discentes acerca dos assuntos estudados. No entanto, têm-se indicativos de que os questionamentos estiveram menos presentes do que o almejável. Ademais, o debate de ideias ocorreu em um nível ainda muito embrionário, constituindo-se em um limite com possíveis implicações nas aprendizagens dos conhecimentos de Ciências da Natureza. A compreensão desse limite aponta a necessidade de se ensinar os estudantes a debaterem, bem como a importância da mediação docente nesses debates.

\section{CONSIDERAÇÕES FINAIS}

Analisamos o trabalho desenvolvido com quatro estudantes, que manifestaram conhecimentos, dificuldades e demandas diversas. Com isso se teve indicativos de potencialidades e limites da proposta de experimento. Parte das dificuldades que os estudantes vivenciaram parecem se relacionar aos seus conhecimentos sobre como trabalhar em grupo. A centralidade da tomada de decisões em uma estudante, a dificuldade em realizar debates, a perspectiva pouco otimista de parte do grupo em relação a um de seus colegas e o fato de nem todos os estudantes terem assumido as funções que lhes foram atribuídas são questões que estão relacionadas com a avaliação das potencialidades e limites da proposta de atividade experimental.

O responsável pela coordenação do grupo não assumiu sua função e essa acabou centrada em outra estudante, com consequências nem sempre positivas. Assim, na etapa final das atividades poderia ser reservado um espaço para discussão com toda a turma sobre como os grupos dividiram o trabalho, os sucessos, as dificuldades e possíveis encaminhamentos para atividades futuras.

Assim, as funções fixas representaram algum limite. Paradoxalmente tais funções fixas ao longo de 3 atividades experimentais também estiveram vinculadas às potencialidades da proposta de atividade experimental. Parecem ter favorecido as interações no grupo, sobretudo no que se refere aos efeitos da função de 
comunicador, que resultou em uma situação de interdependência positiva (JOHNSON; JOHNSON; HOLUBEC, 1999): o sucesso do comunicador foi entendido como o sucesso de todo o grupo e os demais membros mobilizaram-se para auxiliá-lo em sua tarefa.

É preciso reconhecer que o trabalho em grupo constituiu um espaço para aprendizagens atitudinais (respeito, cooperação e solidariedade). Reitera-se que em certos momentos os estudantes dividiram o trabalho na realização das tarefas e ofereceram auxílio uns aos outros, entre outros aspectos. Soma-se a essa potencialidade outra: a explicitação dos conhecimentos iniciais dos estudantes para serem debatidos no coletivo.

Outra potencialidade da proposta foi o favorecimento das interações entre os estudantes. Para iniciar e manter interações sociais saudáveis e responder de modo adequado quando outra pessoa interage consigo são necessárias habilidades sociais, que, por sua vez, também são resultados de aprendizagens (ESCRIBANO; ALONSO, 2005). Destaca-se a demanda dessas aprendizagens pelo estudante cego, que foi quem mais explicitou dificuldades em interagir e participar das atividades. Há estudos que indicam que parte significativa dos cegos possui dificuldades nessas habilidades (FRANÇA-FREITAS; GIL, 2012; ESCRIBANO; ALONSO, 2005). Isso não é consequência direta da cegueira, mas de seu histórico de socialização. Por outro lado, é justamente a partir das interações sociais que os cegos podem superar os possíveis obstáculos (VYGOTSKI, 1997). O trabalho em grupo pode trazer contribuições para o cego e para os videntes, na medida em que colabora para evoluções em suas formas de interagir, superando a centralidade da visão nas formas de comunicação.

Embora a preocupação com as interações sociais por parte de professores dos anos iniciais que lecionam Ciências da Natureza para estudantes cegos não represente uma novidade (SILVA, 2013), o que apresentamos neste trabalho dá indicativos de que a qualidade das referidas interações precisa ser objeto de atenção e aperfeiçoamento. Em outras palavras, não são quaisquer interações que têm o potencial de favorecer as desejáveis aprendizagens discentes. Também são importantes as interações entre os diferentes professores que atuam com estudantes cegos (professor da turma regular e o professor de educação especial, por exemplo), aspecto que a autora supracitada igualmente sinaliza.

Os limites também podem estar associados a explicações mais complexas. É possível que as compreensões sobre a cegueira que possuem o estudante cego e seus colegas tenham influenciado o processo de ensino e aprendizagem e a dinâmica de trabalho no pequeno grupo. Essas compreensões não foram objeto de análise no trabalho, mas podem constituir futuros objetos de estudo em pesquisas sobre as atividades envolvendo estudantes cegos e videntes em pequenos grupos — não somente nos anos iniciais do ensino fundamental como em outros níveis educacionais.

\section{REFERÊNCIAS}

BACHELARD, G. A formação do espírito científico: contribuição para uma psicanálise do conhecimento. Rio de Janeiro: Contraponto, 1996.

BONALS, J. O trabalho em pequenos grupos na sala de aula. Porto Alegre: Artmed, 2003. 
BRASIL. Ministério da Educação. Instituto Nacional de Estudos e Pesquisas Educacionais. Sinopse Estatística da Educação Básica: Censo Escolar 2004. Brasília: MEC/INEP, 2004.

BRASIL. Ministério da Educação. Instituto Nacional de Estudos e Pesquisas Educacionais. Sinopse Estatística da Educação Básica: Censo Escolar 2012. Brasília: MEC/INEP, 2014.

BRASIL. Secretaria de Educação Especial. Política Nacional de Educação Especial na Perspectiva da Educação Inclusiva. Brasília: MEC/SEES, 2007

CAMARGO, E. P. O ensino de Física no contexto da deficiência visual: elaboração e condução de atividades de ensino de Física para alunos cegos e com baixa visão. 2005. Tese (Doutorado em Educação) - Faculdade de Educação, Universidade Estadual de Campinas, Campinas, 2005.

CAMARGO, E. P. Saberes docentes para a inclusão do aluno com deficiência visual em aulas de física. São Paulo: Editora UNESP, 2012.

CARNEIRO, M. H. S. Estudo das representações do conceito de nutrição vegetal. In: ENCONTRO NACIONAL DE PESQUISA EM EDUCAÇÃO EM CIÊNCIAS, 2, 1999, Valinhos. Atas... Valinhos: APRAPEC, 1999.

CARVALHO, A. M. P. Uma metodologia de pesquisa para estudar os processos de ensino e aprendizagem em salas de aula. In: SANTOS, F. M. T.; GRECA, I. M. (org.). A pesquisa em ensino de ciências no Brasil e suas metodologias. Ijuí: Unijuí, p. 13-48, 2006.

DELIZOICOV, D.; ANGOTTI, J. A.; PERNAMBUCO, M. M. Ensino de ciências: fundamentos e métodos. São Paulo: Cortez, 2002.

ESCRIBANO, C. C.; ALONSO, M. A. V. Habilidades sociales: Programa para mejorar las relaciones sociales entre niños y jóvenes com deficiencia visual y sus iguales sin discapacidad. Madrid: ONCE, 2005.

EVANGELISTA, F. L. O ensino de corrente elétrica a alunos com deficiência visual. 2008. Dissertação (Mestrado em Educação Científica e Tecnológica) - Universidade Federal de Santa Catarina, Programa de Pós-Graduação em Educação Científica e Tecnológica, Florianópolis, 2008.

FERREIRA, T. I. C. Participar para ver: as interacções sociais nas aulas de Ciências da Natureza como uma prática inclusiva de alunos cegos no $2^{\circ}$ Ciclo do Ensino Básico. 2009. Dissertação (Mestrado em Educação) - Universidade de Lisboa, Faculdade de Ciências, Lisboa, Portugal, 2009.

FRANÇA-FREITAS, M. L. P.; GIL, M. S. C. A. O desenvolvimento de crianças cegas e de crianças videntes. Revista Brasileira de Educação Especial, Marília, v. 18, n. 3, p. 507-526, jul/set. 2012.

FRANCISCO JR., W.; FERREIRA, L. H.; HARTWIG, D. R. Experimentação problematizadora: fundamentos teóricos e práticos para a aplicação em salas de aula de ciências. Química Nova na Escola, São Paulo, n. 30, p. 34-41, nov. 2008.

FRANCISCO, C. A.; QUEIROZ, S. L. A produção do conhecimento sobre ensino de Química nas Reuniões Anuais da Sociedade Brasileira de Química: uma revisão. Química Nova, v.1, n.8, p.21002110, 2008.

GIL-PÉREZ, D. VALDÉS, P. La orientación de las prácticas de laboratorio como investigación: un ejemplo ilustrativo. Enseñanza de las Ciencias, Barcelona, Espanha, v. 14, n. 2, 155-163. 1996.

GONÇALVES, F. O Texto de Experimentação na Educação em Química: Discursos Pedagógicos e Epistemológicos. 2005. Dissertação (Mestrado em Educação Científica e Tecnológica) - Universidade Federal de Santa Catarina, Programa de Pós-Graduação em Educação Científica e Tecnológica, Florianópolis, 2005.

GONÇALVES, F. P.; REGIANI, A. M.; AURAS, S. R.; SILVEIRA, T. S.; COELHO, J. C.; HOBMEIR, A. K. T. A educação inclusiva na formação de professores e no ensino de química: a deficiência visual em debate. Química Nova na Escola, v. 35, p. 264-271, nov. 2013.

GUNSTONE, R. F. Reconstructing theory from practical experience. In: WOOLNOUGH, B. (org.). Practical Science. Milton Keynes: Open University Press, p. 67-77, 1991.

JOHNSON, D. W.; JOHNSON, R. T.; HOLUBEC, E. El aprendizaje cooperativo en el aula. 
Tradução de Gloria Vitale. Buenos Aires: Paidós, 1999.

MEGID NETO, J.; ROCHA, M. B. Práticas de formação de professores para o ensino de Ciências nos anos iniciais do ensino fundamental: uma revisão de literatura. Ensino Em-Revista, v.17, n.1, p.155-176, 2010.

MORAES, R.; GALIAZZI, M. C. Análise Textual Discursiva. 2ª ed. Ijuí: Unijuí, 2013.

OCHAITA, E.; ROSA, A. Percepção, ação e conhecimento nas crianças cegas. In: COLL, C.; PALÁCIOS, J.; MASCHESI, A. (org.). Desenvolvimento psicológico e educação: necessidades educativas especiais e aprendizagem escolar. Porto Alegre: Artes Médicas, p.183-197, 1995.

SANTOS, B. R. G., et al. Pesquisas sobre ensino de Física para alunos com deficiência visual: um estudo exploratório. In: ENCONTRO NACIONAL DE PESQUISA EM EDUCAÇÃO EM CIÊNCIAS, 8, 2011, Campinas. Atas... Rio de Janeiro: ABRAPEC, 2011.

SCHWAHN, M. C.A.; NETO, A. S. A. Ensinando química para alunos com deficiência visual: uma revisão de literatura. In: ENCONTRO NACIONAL DE PESQUISA EM EDUCAÇÃO EM CIÊNCIAS, 7, 2009, Florianópolis. Anais... Belo Horizonte: ABRAPEC, 2009.

SILVA, G. S. F. As intervenções do professor e processo grupal nas aulas de Física: uma análise à luz da teoria de Grupos Operativos. 2008. Dissertação (Mestrado em Ensino de Ciências) - Instituto de Física, Universidade de São Paulo, São Paulo, 2008.

SILVA, M. D. O ensino de Ciências da Natureza nos anos iniciais do ensino fundamental a estudantes com cegueira. 2013. Dissertação (Mestrado em Educação Científica e Tecnológica) - Universidade Federal de Santa Catarina, Programa de Pós-Graduação em Educação Científica e Tecnológica, Florianópolis, 2013.

SILVA, M. D.; GONÇALVES, F. P.; MARQUES, C. A. Práticas pedagógicas em ciências da natureza nos anos iniciais do ensino fundamental com estudantes cegos. Revista Brasileira de Pesquisa em Educação em Ciências, v.15, n.3, p. 497-518, 2015.

SLONGO, I. I. P.; DELIZOICOV, D. Um panorama da produção acadêmica em ensino de Biologia desenvolvida em Programas Nacionais de Pós-Graduação. Investigações em Ensino de Ciências, v.11, n.3, p.323-341, 2006

SOLER, M. A. Didáctica multisensorial de las ciencias: Un nuevo método para alumnos ciegos, deficientes visuales y también sin problemas de visión. Barcelona: Ediciones Paidós Ibérica, 1999.

SUPALO, C. Techniques to enhance instructors' teaching effectiveness with chemistry students who are blind or visually impaired. Jounal of Chemical Education, v.82, n.10, out, 1513-1518. 2005.

VYGOTSKI, L. S. Obras Escogidas V: fundamentos de defectología Madrid: Visor, 1997.

\section{NOTAS}

${ }^{1} \mathrm{~A}$ expressão deficiência é permeada por muitos sentidos, às vezes com conotação pejorativa. Desse modo, optou-se em utilizá-la entre aspas para ser fiel às referências em casos de citação direta/ indireta, quando não é possível suprimi-la.

Submetido em 27/05/2016

Aprovado em 09/11/2017

\section{Contato:}

Programa de Pós-graduação em Educação Científica e Tecnológica,

Universidade Federal de Santa Catarina, Caixa Postal 476

CEP 88.040-970, Florianópolis - SC, Brasil. 